\title{
O TURISMO COMO TEMA DE PESQUISA NO ÂMBITO DA PÓS- GRADUAÇÃO STRICTO SENSU EM GEOGRAFIA NO BRASIL
}

\author{
Christiano Henrique da Silva Maranhão ${ }^{1}$
}

\section{Resumo}

O artigo busca mapear os estudos (teses e dissertações) que optam pelo turismo como tema de pesquisa, no âmbito dos programas brasileiros de pós-graduação stricto sensu em Geografia, e analisar a relevância da temática do turismo para a laboração desses estudos. Trata-se de uma pesquisa exploratório-analítica de viés qualitativo. Identificaram-se 814 estudos que optam pelo turismo enquanto temática de pesquisa, dos quais 641 são dissertações e 173 são teses. Destes, 491 estudos examinam o turismo como temática central e 323 estudos analisam o turismo de forma complementar ao escopo pesquisado. Conclui-se que o turismo, enquanto temática para teses e dissertações dos programas brasileiros de pós-graduação stricto sensu em Geografia é relevante, e que a Geografia continua destacando-se como uma das ciências que mais fomenta estudos a partir da relação sinérgica com o turismo.

Palavras-chave: Turismo. Tema de Pesquisa. Estudos (teses e dissertações). Pós-graduação. Geografia.

\section{TOURISM AS A RESEARCH TOPIC IN THE CONTEXT OF STRICTO SENSUPOSTGRADUATE STUDIES IN GEOGRAPHY IN BRAZIL}

\begin{abstract}
The article seeks to map the studies (theses anddissertations) that opt for tourism as a research theme, inthe context of Brazilian programs of stricto sensupostgraduate in geography, and to analyze the relevance ofthe theme of tourism for the working of these studies. This is an exploratory-analytical research of qualitative bias. Identified 814 studies that opted for tourism as a research theme, of which 641 are dissertations and 173 are theses. Of these, 491 studies examine tourism as a central theme and 323 studies analyze tourism in a complementary way to the researched scope. It is concluded that tourism, as a theme for theses and dissertations of Brazilian programs of stricto sensu postgraduate in geography is relevant, and that geography continues to be highlighted as one of the sciences that most fosters studies from the relationship Synergistic with tourism.
\end{abstract}

Key-words: Tourism. Research Theme. Studies (theses and dissertations). Postgraduate studies. Geography.

\footnotetext{
${ }^{1}$ Doutor em Geografia pela Universidade Federal do Rio Grande do Norte. Bacharel e Mestre em Geografia pela Universidade Federal do Rio Grande do Norte. Assessor Técnico da ONG RESPOSTA - Responsabilidade Social Posta em Prática. E-mail: christianomaranhao@gmail.com.
} 


\section{EI TURISMO COMO TEMA DE INVESTIGACIÓN EN EL ÁMBITO DE LA POST-GRADUACIÓN STRICTO SENSU EN GEOGRAFÍA EN BRASIL}

\section{Resumen}

El artículo busca mapear los estudios (tesis y disertaciones) que optan por el turismo como tema de investigación, en el ámbito de los programas brasileños de postgrado stricto sensu en Geografía, y analizar la relevancia de la temática del turismo para la labor de esos estudios. Se trata de una investigación exploratorio-analítica de sesgos cualitativo. Se identificaron 814 estudios que optaron por el turismo como tema de investigación, de los cuales 641 son disertaciones y 173 son tesis. De ellos, 491 estudios examinan el turismo como tema central y 323 estudios analizan el turismo de forma complementaria al ámbito investigado. Se concluye que el turismo, como temática para tesis y disertaciones de los programas brasileños de postgrado stricto sensu en Geografía es relevante, y la Geografía continúa destacándose como una de las ciencias que más fomenta estudios a partir de la relación sinérgica con el turismo.

Palabras-clave: Turismo. Tema de Investigación. Estudios (tesis y disertaciones). Posgraduación. Geografía.

\section{INTRODUÇÃO}

A contemporaneidade testemunha um avanço significativo do turismo enquanto tema de pesquisa científica. É possível destacar o esforço de seus pesquisadores em avançar no saber agregado a essa área, como também é permitido pontuar o interesse de pesquisadores de ciências contíguas em estudá-lo, em decorrência dos impactos que o turismo produz em seus diferentes objetos de pesquisa.

Reconhece-se que a atuação conjunta entre áreas distintas do saber é consequência da partilha de problemas globais, como a desigualdade socioeconômica e a degradação ambiental, por exemplo, que, transformados em questionamentos científicos, solicitam um trabalho contíguo entre campos disciplinares distintos (MARANHÃO, 2010; MENEGHEL, 2007). Pensando assim, e diante de uma realidade globalizada, parece dissonante manter-se apático à disposição de relacionar-se e de cooperar com outros campos de investigação.

Imerso nessa conjuntura macro, entende-se o turismo como um fenômeno socioespacial que se articula com distintas interfaces (econômica, social, ambiental, dentre outras), particularidade que o habilita como temática de pesquisa de diferentes ciências, sendo ele historicamente estudado pela Geografia, foco deste artigo.

Destarte, sabe-se que a Geografia traz em sua gênese (século XIX) a síntese do conhecimento de várias ciências, base de seu próprio alinhamento epistemológico (BECKER, 
2014), e como desdobramento ainda é permitido sublinhar uma predisposição geográfica por análises que envolvem uma gama de temas, que foi intitulada por Carlos (2002, p. 161) de "multiplicidade temática e teórico-metodológica", sempre condicionada pela presença de novas racionalidades postas no espaço.

Ao meditar sobre a provável origem da relação entre a Geografia e o turismo, recordase o final do século XIX, diante da formalização científica da ciência geográfica. Relata-se que o geógrafo alemão Alexandre Von Humboldt esquematizou metodologicamente os dados que observava durante suas viagens, a partir da produção de um inventário de elementos naturais e de suas respectivas localizações (MORAES, 2007). Nota-se, diante dos relatos que a experiência da viagem, mesmo que ainda não configurasse como um instrumento do turismo moderno, serviu de ferramenta metodológica para o aludido geógrafo alemão, na sua tentativa de organizar metodicamente o conhecimento então fomentado.

Em virtude do incremento que o turismo vem recebendo na academia e no mercado, é permitido destacar a afinidade que ele mantém com o conteúdo geográfico. Observa-se que a relação estabelecida entre pessoas e lugares, diante da prática do turismo, evidencia uma presença relacional de fluxos (de pessoas, mercadorias e capital) e de infraestrutura (urbana e turística) no espaço, reconhecido como elo-base que ampara essa relação.

O espaço é o centro das apreensões de vários campos de pesquisa. Para alguns, é objeto de estudo, e para outros é um meio de trabalho. Ou seja, O espaço "é o mais interdisciplinar dos objetos concretos" (SANTOS; SOUZA, 1991, p. 1). E esse mesmo espaço, entendido como natureza e sociedade em processo dinâmico, denomina-se de espaço geográfico, objeto de estudo da Geografia (SANTOS, 2009).

Desse modo, compreende-se que o espaço geográfico resulta da ação-relação humana sobre o ambiente natural, promovendo uma constante mutação espacial, sobretudo devido à inserção de novos objetos e técnicas (BECKER, 2014). É nesse momento que o turismo passa a atuar sob esse espaço por meio da afinidade entre os deslocamentos com as materialidades, delineando uma digital geográfica da práxis do turismo, revelando problematizações específicas que chamam atenção dos geógrafos. Sabendo disso, Gastal (2002, p. 8) diz que "nesse turismo que é deslocamento [...] as questões do espaço têm sido encampadas pela Geografia". Nota-se a articulação do turismo com uma base territorial que justifica sua aproximação do espaço geográfico. 
As primeiras contribuições de análises geográficas sobre o turismo surgiram na França, por meio de autores como Mariot (1969), Campbell (1967) Pearce (1998), dentre outros (LIMA; REJOWSKI, 2011). Admite-se que a Geografia inicia os estudos sobre o turismo pontuando os enclaves produzidos pelos deslocamentos no meio natural, "na medida em que territórios eram desmatados para construção de Resorts" (BARRETTO; SANTOS, 2005, p. 361 grifo do autor).

No cenário brasileiro é possível citar a tese do professor Dr. Armando Corrêa da Silva, intitulada $O$ litoral norte do estado de São Paulo: formação da região periférica e defendida em 1975, no Departamento de Geografia da Faculdade de Filosofia, Letras e Ciências Humanas da Universidade de São Paulo (USP), como o primeiro esforço acadêmico-científico da geografia brasileira em função da temática do turismo (CASTRO, 2006). A aludida tese fez uma leitura elementar, reflexo direto de uma atividade turística que ainda carecia de estrutura de mercado e organização estatal (SILVA, 1975).

Entretanto, quando se busca o primeiro trabalho geográfico em nível de pós-graduação stricto sensu no Brasil que estudou o turismo como temática principal de pesquisa, destaca-se a tese de Kleber M. B. Assis, intitulada O turismo interno no Brasil, datada de 1976 e defendida no Departamento de Geografia da Universidade Federal do Rio Grande do Sul (RODRIGUES, 2001). Esse estudo apresentava um perfil descritivo, dotado de um expressivo volume de dados que sinalizava para os aspectos econômicos da atividade, já destacando certa centralidade da interface econômica do turismo.

Já quando se trata de estudos produzidos na área do turismo, igualmente é possível ilustrar esforços em torno do relacionamento para com a Geografia. Sublinha-se que no início da década de 1980, uma pesquisa de Jafari e Aaser analisou um empírico de 157 teses sobre o turismo produzidas nos Estados Unidos entre os anos de 1951 a 1987, com base nos arquivos do Dissertation Abstract Index (DAI). Constatou-se que a Geografia é uma das áreas científicas mais tradicionais a produzir conhecimento abordando a temática do turismo (LIMA; REJOWSKI, 2011).

Diante desses fatos, este artigo busca mapear os estudos (teses e dissertações) que optam pelo turismo como tema de pesquisa, no âmbito dos programas brasileiros de pósgraduação stricto sensu em Geografia, e com isso, analisar a relevância (centralidade e/ou complementaridade) da temática do turismo para a elaboração dessas pesquisas.

Este estudo se justifica por atestar que a Geografia é uma das ciências que mais se debruça e coopera historicamente para a construção de um conhecimento acerca do turismo. 
Entende-o como um fenômeno socioespacial e/ou atividade produtiva que consegue moldar e consumir territórios (produzindo e reproduzindo espaços), peculiaridade que o insere no sistema de fluxos e materialidades, e revela a impossibilidade de existir turismo sem uso do espaço (AZEVEDO et al., 2013).

Outro fato que ratifica o objetivo proposto é a compreensão do turismo como peça relevante de composição da dinâmica de mundo, sobretudo na contemporaneidade, fator que acaba permitindo que seu conteúdo estimule o interesse geográfico. Silva (2012, p. 48-49) afirma que:

A renovação teórica incitada pela Geografia nos últimos 50 anos retrata a preocupação que a referida ciência tem em estudar temas atuais. Observando as ciências humanas e sociais, a Geografia tem se apresentado como uma das que mais tem se aberto aos debates acadêmicos sobre variados temas [...] O turismo representa apenas uma parcela das várias que compõem o espaço geográfico.

Paralelamente, reforça-se também a necessidade de avanços e atualizações nos paradigmas que estudam o turismo. O esforço aqui se centraliza no viés geográfico, mas se reconhece que esse formato de pesquisa pode ser replicado para outras ciências associadas ao turismo, visando expandir o processo de levantar e analisar dados que possibilitem a construção de um arcabouço teórico fundamentado sobre a forma como o turismo é estudado por diferentes ciências e abordagens.

Por fim, a finalidade central deste estudo não é a de esgotar a discussão, mas antes lançar novas questões que possam suscitar debates originais e contribuir para a ampliação da sinergia entre o turismo e a Geografia, vislumbrando ganhos para turismólogos, geógrafos e outros pesquisadores interessados nesta temática.

\section{METODOLOGIA}

A escolha apropriada de uma metodologia faz parte da meta de fornecer um direcionamento adequado à leitura do estudo. Assim, o leitor deve ter acesso, por meio da metodologia, a "uma visão do roteiro utilizado; elementos para compreender, identificar e avaliar os procedimentos usados" (KÖCHE, 2013, p. 144). Logo, é função da metodologia explicar as relações firmadas durante o processo de elaboração, operacionalização e finalização da pesquisa.

Sabendo disso, e com base em autores que discutem processos metodológicos (GONÇALVES, 2005; GIL, 2007; VEAL, 2011), é permitido dizer que este estudo apresenta um caráter exploratório-analítico. Por reconhecer o turismo como uma área de estudo recente, 
ratifica-se a correlação sequencial entre as ações de explorar, analisar, descrever e explicar os fatos; evitando limitar-se a descrição simples, que isolada de outros atos não produz avanços significativos.

Este estudo também se alicerça em um viés qualitativo, sobretudo por ser uma forma adequada de entender a natureza de um tipo de conhecimento já produzido (RICHARDSON, 2008). Destaca-se que dados quantitativos também foram utilizados, visando integrar, complementar e expandir as interpretações feitas.

Relata-se que a definição do empírico está diretamente associada com a triagem dos estudos (teses e dissertações) em nível da pós-graduação stricto sensu em Geografia no Brasil, que apresentam análises sobre a temática do turismo. Sobre o motivo que direcionou a escolha das teses e dissertações como empírico, informa-se que a representatividade desses estudos para a conjuntura acadêmico-científica do Brasil foi decisiva para tal.

Nota-se, frequentemente, que esses estudos estão vinculados a pesquisas que se desdobram desde a graduação, e vêm avançando e promovendo um efeito multiplicador nas pesquisas da pós-graduação, fomentando surveys, papers, temáticas de eventos científicos, dentre outros resultados. Ou seja, teses e dissertações são o produto final para onde migram e de onde partem, simultaneamente, as análises que retratam a excelência da pesquisa acadêmica no Brasil. Somente depois dessa definição, foi que ocorreu a seleção da plataforma de armazenamento dos dados e a forma de triagem.

O Banco digital de teses e dissertações da Coordenação de Aperfeiçoamento de Pessoal de Nível Superior (Capes) foi eleito como plataforma de armazenamento desses estudos, por apresentar elementos que o habilitam para a operacionalização das categorias de análise e coleta de dados.

A decisão pela assistência da Capes se justifica em função da sua abrangência, no que tange à coleta e armazenamento de teses e dissertações em nível nacional, uma vez que todas as pesquisas catalogadas no seu Banco digital são fornecidas diretamente pelos programas de pós-graduação do Brasil, por meio de um sistema denominado até o ano de 2014 de Coleta, que depois passou a ser nomeado de Plataforma Sucupira. Além disso, a opção pela Capes garantiu abrangência no que se refere à participação de todos os programas brasileiros de pósgraduação stricto sensu em Geografia conceituados pela aludida agência de fomento do conhecimento científico no Brasil (CAPES, 2015).

Complementar à seleção da aludida plataforma de armazenamento digital, foram definidas categorias de análise, a fim de nortear o processo de coleta. Desse modo, as 
palavras-chave: turismo, fenômeno turístico e atividade turística, determinaram quais trabalhos estavam validados para o download e posterior análise.

Relata-se que para o estudo ser considerado participante do empírico da pesquisa, ele teria de apresentar no seu título ou no resumo alguma das palavras-chave destacadas. A escolha desses termos está condicionada ao inerente caráter dual do turismo (CASTRO, 2006). Isto é, o turismo podendo ser estudado como um vetor de produção do capital, associado à ideia de atividade turística, ou o turismo analisado como vetor de desenvolvimento, reconhecido como fenômeno socioespacial complexo.

Dito isto, relata-se que no segundo semestre do ano de 2016 foi enviado um e-mail para a secretaria da Capes, via o Programa de Pós-graduação e Pesquisa em Geografia (PPGe) da UFRN, solicitando um levantamento de estudos geográficos (teses e dissertações), no âmbito da pós-graduação stricto sensu em geografia no Brasil, que pesquisam sobre o turismo. Na ocasião também foram repassados os parâmetros da seleção, permitindo que a equipe da Capes emitisse uma listagem dos estudos geográficos que elegeram o turismo como temática de pesquisa, ordenando-os por títulos, resumos, palavras-chave, autor e e-mail de contato. Concluída a coleta de dados, iniciou-se a ordenação do material, visando possibilitar uma interpretação coerente. Todos os trabalhos foram numerados em ordem crescente, e identificados com a Letra D (para dissertações) e T (para teses).

Após esse primeiro crivo, a análise migrou para outros fragmentos do texto, a saber: sumário, introdução e conclusões, buscando-se identificar elementos que retratem a forma como o turismo foi analisado pelas pesquisas. A escolha desses itens alinha-se às normativas da Associação Brasileira de Normas Técnicas (ABNT), que apontam para as seguintes especificidades: (a) no que se refere ao sumário, é possível visualizar em tópicos, os principais temas trabalhados pelas pesquisas, (b) na introdução estão contidos: problemática, problema, razões que justificam o estudo, objetivos e a metodologia do trabalho, (c) já nas conclusões, localiza-se o momento que cada autor expõe suas opiniões sobre o assunto analisado (ISKANDAR, 2012).

Alinhado a esse direcionamento, optou-se pela técnica da análise de conteúdo (BARDIN, 2004), por entendê-la como uma técnica que pode ser aplicada em conteúdos diversos, sempre buscando a informação que está nas entrelinhas. Sua operacionalização foi esboçada em três etapas: (a) Pré-análise: seleção e leitura superficial do material coletado; (b) Exploração detalhada: quantificação, codificação e categorização informacional do empírico 
coletado; (c) Interpretação: explanação de inferências e resultados relacionados às questões levantadas pela investigação. Somado a isso, destaca-se ainda a utilização do levantamento bibliográfico como outra ferramenta técnica apropriada para a apreensão de dados qualitativos (GONÇALVES, 2005). De posse desses subsídios, foi possível analisar a relevância da temática do turismo na estruturação de cada estudo e as nuances dessa relação.

\section{BREVES NOTAS SOBRE A PRODUÇÃO DO CONHECIMENTO EM TURISMO}

Refletir sobre o turismo enquanto temática que produz conhecimento científico é uma tarefa desafiadora. Sabe-se que o turismo se reveste de características que acompanham a evolução do sistema capitalista e sua rápida promoção esteve fortemente atrelada às transformações técnico-científicas iniciadas com o término da Segunda Guerra Mundial (1939-1945).

Por essa razão, admite-se que o acontecer turístico ocorreu paralelo aos avanços nos transportes, telecomunicações e prestação de serviços de forma geral, que, sinérgicos ao acesso à informação e conquistas trabalhistas, compuseram uma conjuntura que cooperou para uma ampliação da área de atuação do turismo, e consequentemente para os estudos dos desdobramentos da práxis da aludida atividade. Para Azevedo (et al. 2013, p. 8), a expansão do turismo relaciona-se com mudanças marcadas pelo

\footnotetext{
Meio técnico-científico, produção e difusão de informação, maior eficiência no sistema de transporte, sobretudo aéreo, garantindo rapidez e agilidade no deslocamento, melhorias na oferta de serviços turísticos, [...] marketing turístico, políticas de promoção, associando ações do setor público e privado, potencial natural, $[\ldots]$ dentre outras características e condições.
}

Logo, o turismo tornou-se um aspecto marcante da sociedade moderna, muito embora a sua compreensão ainda seja limitada (na maioria das vezes) ao seu peculiar movimento econômico. A limitação não está em estudar o turismo a partir de uma abordagem econômica, uma vez que não se pode negar que foi somente através deste viés que o turismo começou a atrair atenção mundial e impactar (positiva e negativamente) vários setores, motivando análises amparadas por plataformas que o estudam por diferentes perspectivas (de defesa, advertência, de adaptação, de conhecimento científico e como bem público) (JAFARI, 1994, 2005). A saturação ocorre na forma como os agentes hegemônicos do turismo (Estado e Mercado) justificam e centralizam o esforço dedicado para com a atividade turística, restringindo o impacto social do turismo à geração de emprego e renda. 
Destarte, percebe-se que o desafio de produzir conhecimento sobre o turismo não se restringe apenas aos turismólogos. É notório o interesse de diversas áreas em estudar o turismo, e dotá-lo de significações e ressignificações. Diante das distintas abordagens que estudam o turismo, tem-se que a conceituação do turismo varia conforme a área que o estuda, satisfazendo as necessidades próprias de cada ciência que o analisa, resultando em diversas abordagens para o mesmo fenômeno.

É sabido que pesquisadores de diversas áreas (Antropologia, Sociologia, Geografia, Economia, Administração dentre outras) têm estudado o turismo como objeto de análise de suas dissertações e teses (HOLANDA et al., 2012), e com frequência essas iniciativas começam a partir da relação e/ou interferência que o turismo estabelece com os objetos de estudo das ciências associadas, fazendo com que, a posteriori, seja ofertado um conhecimento especializado sobre uma determinada interface do turismo.

Neste momento, é imperativo fazer uma ressalva: não se busca nesta análise apontar e/ou defender alguma posição científica específica e responsável por uma epistemologia do turismo. Antes, busca-se destacar alguns episódios sobre a estruturação do conhecimento em turismo, diante de sua brevidade como área de estudo.

Dito isso, e diante do cenário internacional, destaca-se que o alemão é o idioma mãe referente ao conhecimento turístico no Ocidente (idioma de importantes geógrafos). Sabe-se que os primeiros apontamentos referentes ao conhecimento técnico-científico em turismo começaram a ser produzidos na Alemanha, Itália, Suíça e Áustria, durante a primeira metade do século XIX (PANOSSO NETTO; TRIGO, 2016). Com efeito, é permitido destacar as principais escolas que predominaram diante desse contexto de pesquisas produção de conhecimento sobre o turismo: (a) Escola Alemã (Berlinesa), pautada na abordagem econômica, (b) Escola Francesa, focando em questões sociais, e (c) a Escola Polonesa trazendo o debate psicológico (ACERENZA, 2002).

Ainda no contexto internacional, sabe-se que as décadas de 1960 e 1970 foram marcadas por estudos que se guiavam pelo viés socioantropológico do turismo. Durante esse período também surgiu uma expressiva visão de mercado do turismo. Mas foi somente na década de 1980 que as questões ambientais começaram a ser pauta, e a comunidade acadêmica passou a se orientar por questões norteadas pelo conceito de sustentabilidade (NECHAR, 2011). 
Contudo, reconhece-se que a década de 2000 foi assinalada pelo fomento de pesquisas mais complexas, iniciando um movimento crítico sobre o discurso positivista das benesses que o turismo promove, e simultaneamente adotando uma postura acrítica para com a quantificação, neutralidade, objetividade, validade e confiabilidade (PRITCHARD; MORGAN, 2007), e de igual modo para com o viés produtivista (URRY, 1990).

Já meditando em escala nacional, sabe-se que o turismo aconteceu no Brasil como consequência das características físicas do território nacional, uma vez que a busca por praias, sol e ecossistemas relativamente preservados correspondia, e ainda corresponde, à "[...] parte das expectativas de uma parcela significativa da demanda mundial de turistas" (CRUZ, 2000, p. 133). Desde então, o Brasil passou a ser uma opção para fluxos turísticos diversos, dentre outros destinos que apresentam recursos similares.

Não se pode precisar o momento exato em que o Brasil é reconhecido como uma possibilidade efetiva para o turismo, no entanto, sabe-se que a primeira iniciativa pública em torno da atividade no país data de 1930, momento marcado pela desarticulação, falta de planejamento e inexistência de prerrogativas ministeriais (ENDRES, 2012).

Passado esse período de decretos-leis desconexos e falta de representatividade estatal, a atividade do turismo no Brasil passou a exigir demandas mais específicas: políticas públicas de ordenamento e promoção, programas, planos, representação ministerial e por capital humano especializado. Assim, em 1970, inicia a oferta de cursos de graduação em turismo no Brasil. Nessa época vigoraram dois modelos de formação em turismo: na Faculdade Morumbi, de caráter profissionalizante e com foco no mercado, e na Universidade de São Paulo, de caráter mais científico e centrado na academia (DENCKER, 2006).

Sobre a conjuntura da pós-graduação stricto sensu em turismo no Brasil, sabe-se que os primeiros programas de pós-graduação específicos em turismo datam sua instituição a partir da década de 1990, a saber: o Mestrado em Turismo e Lazer da USP (1993 a 1998), e o Mestrado em Turismo e Hotelaria da Universidade do Vale do Itajaí (UNIVALI), em 1997, (REJOWSKI, 2010).

Com efeito, pontua-se que a produção científica sobre turismo no Brasil ainda se desenvolvia no final da década de 1990 (REJOWSKI, 1996), e somente aos poucos essa realidade foi se modificando, sobretudo a partir dos anos 2000, em que se percebe um aumento significativo da bibliografia especializada, trabalhos de conclusão de curso de graduação, dissertações e teses, artigos científicos publicados em anais de eventos e em periódicos específicos do turismo. Alerta-se que a produção de pesquisas sobre turismo não se 
restringia apenas aos programas específicos da área, antes abarcava programas do âmbito das ciências humanas e sociais, mas não restritas a estas (SCHLÜTER, 2000).

$\mathrm{Na}$ contemporaneidade, o cenário da pós-graduação em turismo no Brasil conta com 11 programas de pós-graduação, que juntos ofertam 15 cursos: 08 de mestrado acadêmico, 04 de doutorado e 03 de mestrado profissional, espacializados por 10 Instituições de Ensino Superior do Brasil. Os aludidos programas de pós-graduação em turismo estruturam-se a partir de 11 áreas de concentração que se ramificam por 22 linhas de pesquisas.

Atualmente, ainda é permitido destacar sobre a pós-graduação em turismo: o fortalecimento das bases de conhecimento, o amadurecimento associativo dos programas de pós-graduação, a inserção cooperativa de nível internacional e a estabilização de periódicos científicos são algumas conquistas que ratificam o fomento da pesquisa em turismo no Brasil, não só considerando o montante quantitativo, mas também a qualidade dos trabalhos, desde o início do século XXI. Para Leal (2014, p. 145), “a criação de grupos de pesquisa [...] para tratar de aspectos relacionados ao estudo crítico do turismo também demonstra [...] maturidade que a produção do conhecimento em turismo no país vem conquistando".

Por fim, entende-se que inexiste consenso sobre o melhor paradigma para entender e produzir conhecimento na área do turismo. Antes, é de comum acordo que o estudo em turismo necessita de uma abordagem consistente, podendo ou não fazer uso de contribuições teóricas e metodológicas de outras áreas de pensamento. Entende-se que para se estudar o turismo, antes se faz necessário entender à complexa multiplicidade do ser humano, reforçando a ideia do estudo do turismo como um desafio, aqui sinônimo de oportunidade.

\section{HISTÓRICO E DESAFIOS DA GEOGRAFIA NO BRASIL}

Até a década de 1930, a geografia no Brasil era apenas uma disciplina de ensino secundarista e só despertava interesse em militares, políticos e mercadores. O conhecimento geográfico nessa época estava disperso (DANTAS, 2011). Contudo, pontua-se alguns fatos que retratam a gênese de um conhecimento geográfico tipicamente brasileiro e os seus desafios de âmbito nacional.

A constituição da Geografia no Brasil divide-se em dois momentos: o primeiro (até 1930) é marcado pela informalidade dos viajantes, cronistas e naturalistas. Dedicavam-se aos estudos das relações entre natureza, paisagem e formas de organização, visando conhecer o território nacional. A pesquisa pautava-se na descrição, classificação, distribuição e 
localização das paisagens brasileiras, destacando questões como a ocupação colonial portuguesa, o uso do espaço, dentre outras (MOREIRA, 2007).

No segundo momento (entre as décadas 1930 e 1940), já se nota um caráter mais formal, consequência da chegada de geógrafos estrangeiros para lecionar no país. A efetiva produção do conhecimento geográfico no Brasil inicia-se com Pierre Deffontaines (18941978), que, chegando a São Paulo em 1934, fundou o curso de geografia na USP, tornando-se o geógrafo que mais influenciou a formatação do pensamento geográfico brasileiro. Em seguida, sublinha-se a contribuição de Pierre Monbeig (1908-1987), com estudos sobre as cidades brasileiras e ensino da geografia. Ambos são considerados como fundadores da Geografia no Brasil, sempre buscavam analisar "a realidade geográfica do espaço brasileiro" (MOREIRA, 2014, p. 27).

Assim, entre os anos de 1934 e 1939, surgem os primeiros geógrafos egressos dos cursos ofertados na USP e as primeiras publicações específicas (Revista Brasileira de Geografia, Boletim Geográfico e Anais de Geografia), e com elas vieram as pesquisas vinculadas aos institutos (Instituto Brasileiro de Geografia e Estatística - IBGE e Instituto Joaquim Nabuco). Paralelo a isso, surgem também as primeiras obras dos geógrafos franceses sobre o Brasil, como: Geografia humana do Brasil (Deffontaines, 1939); Pioneiros e fazendeiros de São Paulo (Monbeig, 1952). Inicia-se a fase acadêmica da geografia no Brasil (MOREIRA, 2014).

Dito isto, segue a exposição de alguns episódios que determinaram o impulso acadêmico inicial para a Geografia no Brasil: (a) a criação, em 1934, do IBGE, primeira instituição que incluiu geógrafos nas pesquisas sobre o conhecimento do território nacional; (b) a fundação da USP (1934) e da Universidade do Distrito Federal (1935), atualmente conhecida de Universidade Federal do Rio de janeiro (UFRJ), permitindo o ensino geográfico em nível superior; e (c) a fundação (1934) da Associação dos Geógrafos Brasileiros (AGB), por Pierre Deffontaines, expandindo nacionalmente a pesquisa científica em geografia no Brasil. Como saldo, surge a primeira tese brasileira em geografia (1944), de autoria da professora Maria da Conceição Vicente de Carvalho, intitulada Santos e a Geografia Urbana do Litoral Paulista. Nas outras regiões do país esse movimento acadêmico ocorria com menor intensidade (DANTAS, 2011).

Apesar disso, o conhecimento geográfico no Brasil só se efetiva na década de 1950, ocasião em que a Geografia clássica chega ao seu auge e, concomitantemente, inicia-se uma crise geográfica de repercussão mundial. Essa década tornou-se o divisor de águas para a 
Geografia mundial e para as projeções brasileiras. A crítica, gene do movimento de renovação geográfica, apontava para a negligência com a questão epistemológica, para a farsa da neutralidade e ingenuidade científica (questão ideológica), para a fragilidade do discurso (questão teórico-metodológica), para a propensão ao gueto (isolamento disciplinar), dentre outras. Fez surgir duas perspectivas: uma de viés funcionalista e outra de caráter neopositivista (MOREIRA, 2007).

É oportuno frisar que a Geografia brasileira inicialmente recebia impulsos da cena internacional, e por isso experimentou as matrizes científicas de geógrafos internacionais como: Reclus, La Blache, Ratzel e Brunhes. Com efeito, perante a realização do Congresso da União Geográfica Internacional (UGI), no Rio de Janeiro, em 1956, é que se atesta o amadurecimento e o reconhecimento internacional de uma Geografia fomentada genuinamente no Brasil. Os geógrafos envolvidos na operacionalização do referido evento, organizaram todo material que subsidiou o congresso, fornecendo base para uma Geografia brasileira de características específicas (MOREIRA, 2014).

No ano de 1978, diante de um encontro da AGB, a Geografia brasileira já vivenciava uma fase de consolidação, com grupos de estudiosos espalhados pelo país, militando em função da crítica e da renovação do pensamento geográfico. Foi exatamente nesse encontro internacional que se aglutinaram as ideias que precipitam a crise da ciência geográfica (MOREIRA, 2007). Percebe-se aqui, que o pensamento geográfico brasileiro já vivenciava um processo de empoderamento por parte de seus estudiosos, com relação às realidades postas na época. Esse interesse por análises históricas e por questões atuais acaba certificando o turismo como um tema a ser estudado pela Geografia, justamente por ele intervir na dinâmica de mundo.

O cenário acadêmico da Geografia brasileira na atualidade é bem diferente do início da década de 1930. Dentre as 48 áreas de avaliação que a Capes apresenta, a Geografia compõe a seção das Ciências Humanas e se expressa academicamente por meio de 65 programas brasileiros de pós-graduação stricto sensu distribuídos pelas cinco regiões do país, a partir de 54 IES, com destaque para a região sudeste, que lidera em números de programas, em número de cursos de doutorado e na quantidade de teses e dissertações (PLATAFORMA SUCUPIRA, 2018).

É permitido informar, ainda, que o cenário acadêmico da área de Geografia no Brasil disponibiliza atualmente 62 cursos de Mestrados acadêmicos, 3 cursos na modalidade de 
Mestrado profissional e 35 cursos de Doutorado. Complementarmente, relata-se que foram identificadas 36 áreas de concentração, associadas à problematizações regionais. De forma conexa, identificam-se 108 linhas de pesquisa de pós-graduação stricto sensu em Geografia em atividade no Brasil (PLATAFORMA SUCUPIRA, 2018).

É importante destacar que o conhecimento geográfico gerado por esses programas, precisou acompanhar os avanços tecnológicos, como forma de validar suas proposições. Por isso, nota-se uma inserção da tecnologia, motivada pela ampliação das necessidades dos próprios sujeitos, revelando um cenário diferenciado que agrega novas técnicas como: cibergeografia, cibercartografia, geotecnologia, dentre outras.

Outro aspecto contemporâneo que se destaca no campo da Geografia é o que faz menção a uma postura interdisciplinar de seus estudos. Sabe-se que a interdisciplinaridade esteve presente, mesmo que implicitamente, em diferentes contextos do conhecimento geográfico. Atualmente, ela passa a ser motivada pela ampliação do campo das ciências sociais e pelo domínio das técnicas, favorecendo o progresso científico pautado na contribuição de disciplinas contíguas (SANTOS, 2004).

Portanto, os geógrafos precisam reconhecer a análise interdisciplinar como uma importante prerrogativa científica, uma vez que a ciência geográfica faz parte de um complexo cenário que se articula com um arsenal de fenômenos múltiplos (inclusive o fenômeno turístico), operacionalizando-os por meio de um instrumental diverso, atrelado às habilidades e requisitos de uma gama de conteúdos.

Sem embargo, identifica-se que a missão da Geografia contemporânea é realizar uma leitura simultânea da realidade (histórica e atual), e por essa razão a informação geográfica é muito mais útil do que o senso comum imagina. É chegado o momento em que uma nova postura com relação à Geografia é exigida. O movimento da totalidade-mundo retira o conhecimento geográfico de uma possível inércia, e lança-o ao movimento das atualizações. Não reconhecer isso é ignorar a própria história da humanidade.

\section{RESULTADOS}

A análise sobre o mapeamento dos estudos (teses e dissertações) que optam pelo turismo como tema de pesquisa, no âmbito dos programas brasileiros de pós-graduação stricto sensu em Geografia, possibilitou a confecção da Tabela 1, que destaca, dentre os 65 programas brasileiros de pós-graduação stricto sensu em Geografia validados pela Capes, 
apenas os que fomentaram estudos com base na relação estabelecida com a temática do turismo, seguido da quantidade de estudos e suas tipologias.

Tabela 1: Quantitativo de teses e dissertações), no âmbito dos programas brasileiros de pós- graduação stricto sensu em Geografia, que optam pela temática do turismo

\begin{tabular}{|c|c|c|c|c|}
\hline \multirow[b]{2}{*}{ REGIÃO } & \multirow[b]{2}{*}{ IES } & \multicolumn{3}{|c|}{ QUANTIDADE } \\
\hline & & D & $\mathbf{T}$ & Total \\
\hline \multirow{3}{*}{ Norte } & 01-Universidade Federal do Pará & 13 & - & 13 \\
\hline & 02-Fundação Universidade Federal de Rondônia. & 03 & - & 03 \\
\hline & Total de Trabalhos - Região Norte & 16 & - & 16 \\
\hline \multirow{8}{*}{ Nordeste } & 03-Universidade Federal da Bahia & 26 & - & 26 \\
\hline & 04-Universidade Federal do Ceará & 21 & 02 & 23 \\
\hline & 05-Universidade Estadual do Ceará & 35 & - & 35 \\
\hline & 06-Universidade Federal da Paraíba & 07 & - & 07 \\
\hline & 07-Universidade Federal de Pernambuco & 32 & 03 & 35 \\
\hline & 08-Universidade Federal do Rio Grande do Norte & 25 & - & 25 \\
\hline & 09-Fundação Universidade Federal de Sergipe & 15 & 10 & 25 \\
\hline & Total de Trabalhos - Região Nordeste & 161 & 15 & 176 \\
\hline \multirow{6}{*}{$\begin{array}{c}\text { Centro- } \\
\text { oeste }\end{array}$} & 10-Universidade de Brasília & 12 & - & 12 \\
\hline & 11-Universidade Federal de Goiás & 28 & 04 & 32 \\
\hline & 12-Fundação Universidade Federal de Mato Grosso do Sul & 15 & - & 15 \\
\hline & 13-Universidade Federal da Grande Dourados & 04 & - & 04 \\
\hline & 14-Universidade Federal de Mato Grosso & 21 & - & 21 \\
\hline & Total de Trabalhos - Região Centro-Oeste & 80 & 04 & 84 \\
\hline \multirow{13}{*}{ Sudeste } & 15-Universidade Federal de Minas Gerais & 37 & 02 & 39 \\
\hline & 16-Universidade Federal de Uberlândia & 24 & 04 & 28 \\
\hline & 17-Pontifícia Universidade Católica de Minas Gerais & 11 & 03 & 14 \\
\hline & 18-Universidade Federal do Rio de Janeiro & 16 & 16 & 32 \\
\hline & 19-Universidade Federal Fluminense & 09 & 05 & 14 \\
\hline & 20-Universidade Estadual do Rio de Janeiro & 24 & - & 24 \\
\hline & 21-Pontifícia Universidade Católica do Rio de Janeiro & 02 & - & 02 \\
\hline & 22-Universidade de São Paulo & 71 & 54 & 125 \\
\hline & 23-Universidade Estadual de Campinas & 22 & 08 & 30 \\
\hline & 24-Pontifícia Universidade Católica de São Paulo & 04 & - & 04 \\
\hline & 25-Universidade Estadual P. Júlio de Mesquita Filho & 32 & 34 & 66 \\
\hline & 26-Universidade Federal do Espírito Santo & 01 & - & 01 \\
\hline & Total de Trabalhos - Região Sudeste & 253 & 126 & 379 \\
\hline \multirow{11}{*}{ Sul } & 27-Universidade Federal do Paraná & 34 & 13 & 47 \\
\hline & 28-Universidade Estadual de Londrina & 10 & - & 10 \\
\hline & 29-Universidade Estadual de Maringá & 12 & 01 & 13 \\
\hline & 30-Universidade Estadual de Ponta Grossa & 05 & - & 05 \\
\hline & 31-Universidade Estadual do Oeste do Paraná & 02 & - & 02 \\
\hline & 32-Universidade do Rio Grande do Sul & 13 & 04 & 17 \\
\hline & 33-Universidade Federal de Santa Maria & 10 & - & 10 \\
\hline & 34-Universidade Federal do Rio Grande & 01 & - & 01 \\
\hline & 35-Universidade Federal de Santa Catarina & 44 & 10 & 54 \\
\hline & $\begin{array}{c}\text { Total de Trabalhos - Região Sul } \\
\end{array}$ & 131 & 28 & 159 \\
\hline & Total Geral & 641 & 173 & 814 \\
\hline
\end{tabular}

Fonte: dados da pesquisa, 2018. Legenda: D- Dissertações; T- Teses. 
Conforme os dados apresentados na Tabela 1, é possível determinar um significativo montante de 814 estudos produzidos pelos programas brasileiros de pós-graduação stricto sensu em Geografia. Desse quantitativo, 641 são dissertações (nível mestrado) e 173 são teses (nível doutorado). Estas pesquisas estão distribuídas por 35 IES, dentre um total de 51 instituições que ofertam a pós-graduação em geografia no Brasil no ano de 2018. Atesta-se que dos 65 programas de pós-graduação existentes, 44 deles apresentam conectividade com o turismo $(67,70 \%)$, e de forma complementar, 21 programas (32,30\%) não apresentaram nenhum estudo que trate da temática do turismo. Destaca-se, pois, uma expressiva representatividade da temática do turismo nos estudos geográficos (teses e dissertações) no âmbito da pós-graduação no Brasil.

Alerta-se para o fato de que se encontram listados na Tabela 1 apenas 35 programas, faltando 09 para completar o número de 44 programas que apresentam estudos que abordam o turismo. $\mathrm{O}$ fato é que alguns programas apresentam mais de um campus, oferecendo mais de um curso de mestrado e/ou doutorado com perspectivas distintas, como é o caso dos programas vinculados à Universidade de São Paulo, Universidade Federal Fluminense, Universidade Estadual do Rio de Janeiro, Universidade Estadual do Oeste do Paraná, Universidade Federal do Mato Grosso, Universidade Federal do Mato Grosso do Sul, Universidade Federal de Goiás e Universidade Estadual Paulista Júlio de Mesquita Filho, integralizando, assim, os 44 programas brasileiros de pós-graduação stricto sensu em Geografia empenhados nos estudos da temática do turismo.

Continuando com o exame, é permitido verificar dados sobre a expressiva liderança da região sudeste, quando se refere à quantidade de estudos identificados (46,56\%), muito em decorrência de ser a região onde surgiram os primeiros programas de pós-graduação, e, consequentemente, os primeiros cursos de mestrado e doutorado em Geografia no Brasil. Destaca-se na segunda posição a região nordeste, com aproximadamente $21,62 \%$ das produções levantadas, seguida de perto pela região sul, com seus 19,53\%, para, na sequência, vir a região centro-oeste, com 10,31\%, e, por último, da região norte, contabilizando apenas $1,96 \%$ do total de estudos que analisam o turismo.

Essa informação ratifica o cenário já exposto pela Capes, no que se refere à necessidade de interiorização dos programas de pós-graduação sem Geografia no Brasil. Em paralelo, Castro (2006) destaca também o período entre 1975 e 1998, como um recorte em que a produção de estudos geográficos sobre o turismo se centralizava nos programas de pós- 
graduação do sudeste e do sul, decorrente do reduzido número de programas de pósgraduação em geografia fora do eixo sul-sudeste.

Meditando sobre os estudos geográficos que abordam o turismo como tema de pesquisa, percebe-se que após a década de 1990, diante do advento de políticas públicas com foco no turismo, passou a haver uma descentralização na produção desses estudos por outras instituições e regiões do país, com destaque para a região nordeste.

Entende-se que o fomento das políticas direcionadas ao turismo, como foi o caso do Programa de desenvolvimento do turismo (PRODETUR), que iniciou suas ações pela região nordestina (1990), acabou gerando inúmeros impactos espaciais, por meio das obras de mobilidade, saneamento, equipamentos turísticos, dentre outras, e com isso atraindo o interesse de geógrafos e outros pesquisadores. No Gráfico 1, verifica-se a quantificação de estudos geográficos que abordam o turismo, a partir da efetivação das ações postas pelo Estado na forma de políticas públicas.

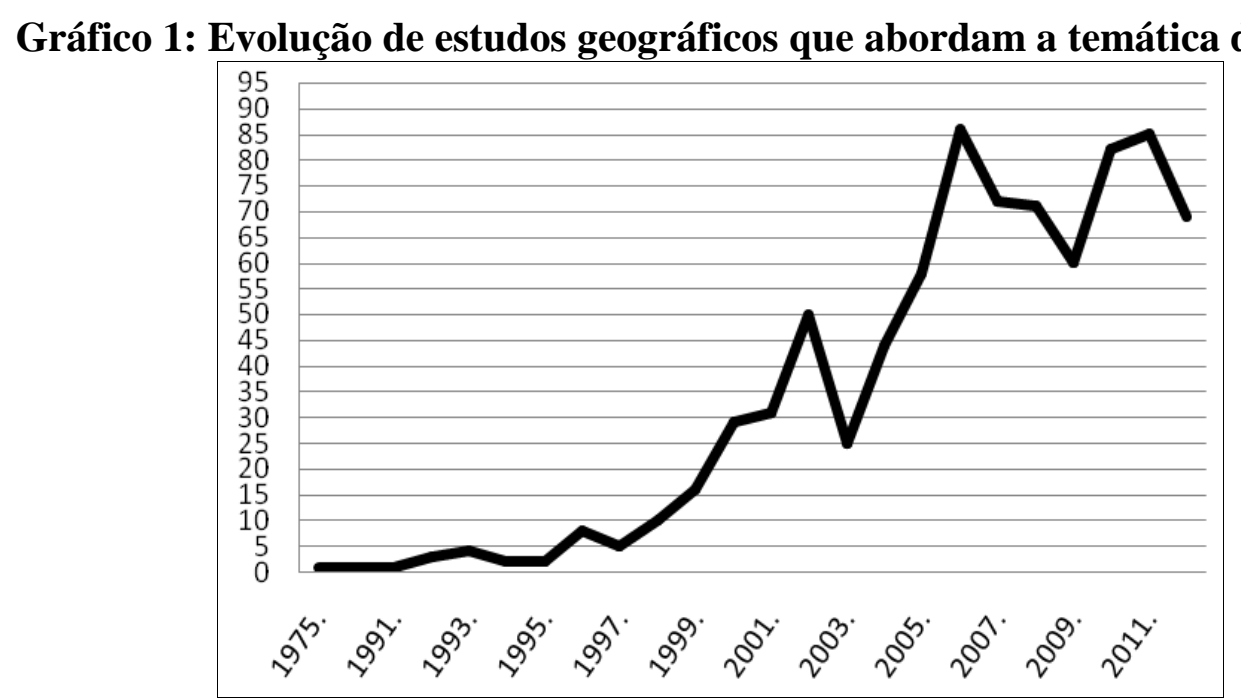

Fonte: dados da pesquisa, 2018.

Nota-se que entre as décadas de 1970 e 1990 havia certa timidez e linearidade no fomento de estudos geográficos (teses e dissertações) que abordassem a temática do turismo. Cenário que retrata a conjuntura que o turismo vivenciava no Brasil, de demanda supérflua, amadorismo, carência de infraestrutura e incentivos governamentais. Contudo, quando se avalia a partir da década de 2000, período em que as materializações do PRODETUR já haviam se espacializado e gerado impactos na sociedade, nota-se um crescimento de pesquisas sobre o turismo, corroborando a ideia de que os estudos surgem como busca de 
respostas aos rebatimentos (positivos e negativos) fomentados perante a efetivação das políticas e programas de turismo no Brasil.

Observa-se um novo pico no ano de 2003, muito associado à criação do Ministério do Turismo (2003), que também fez repercutir impactos a partir de suas ações. Os dados que possibilitaram a elaboração do Gráfico 1 foram retirados dos estudos triados, com destaque para as datas de defesa de cada estudo (teses e dissertações) cruzadas com o período do PRODETUR, uma das poucas políticas públicas com informações detalhadas sobre obras, valores e datas.

Confirmada a relevância da temática do turismo para os estudos (teses e dissertações), no âmbito dos programas brasileiros de pós-graduação stricto sensu em Geografia, parte-se para a análise da representatividade desta temática no momento de estruturação das pesquisas. Para isso, destaca-se no Mapa 1 o quantitativo dos estudos geográficos (teses e dissertações) que abordam o turismo de forma principal ou secundária, espacializado pelas regiões do país.

Fazendo a devida análise, identifica-se que 491 estudos apresentaram a temática do turismo como central, e por isso estruturante da pesquisa realizada. Nota-se, nesses casos, que as pesquisas foram fundamentadas na relação que as distintas categorias de análise geográfica (paisagens, lugares, territórios, regiões, espaço geográfico) estabelecem com a prática do turismo. Tratam das modificações (ambientais, econômicas, socioculturais e políticoterritoriais) que o turismo impõe sobre o espaço.

Diante dos estudos analisados, pontua-se que a categoria causa-efeito se fez presente, onde o turismo é apontado como a causa central de distintas modificações (negativas e positivas) nos espaços onde é fomentado, e em alguns casos, identifica-se um esforço por encontrar a essência do turismo por trás das aparências econômicas e do discurso pronto. Eventualmente, identificam-se análises conjunturais abordando as variáveis que afetam o turismo e suas conexões.

Fazendo alusão aos principais impactos negativos no espaço, promovidos pela atuação desgovernada da prática do turismo, tem-se a expressiva liderança da abordagem ambiental, com destaque para o uso dos recursos das paisagens naturais (praias, florestas, rios, dunas, montanhas dentre outros) como "mercadoria" para ser vendida e consumida pelos fluxos massivos do turismo moderno. Esse direcionamento mal planejado do turismo acaba estimulando estudos que tratam do compromisso social inerente ao Estado, e, de igual modo, pesquisas pautadas na inserção ativa da sociedade civil e residentes locais onde o turismo é promovido. 
Mapa 1: Detalhamento e espacialização dos estudos analisados

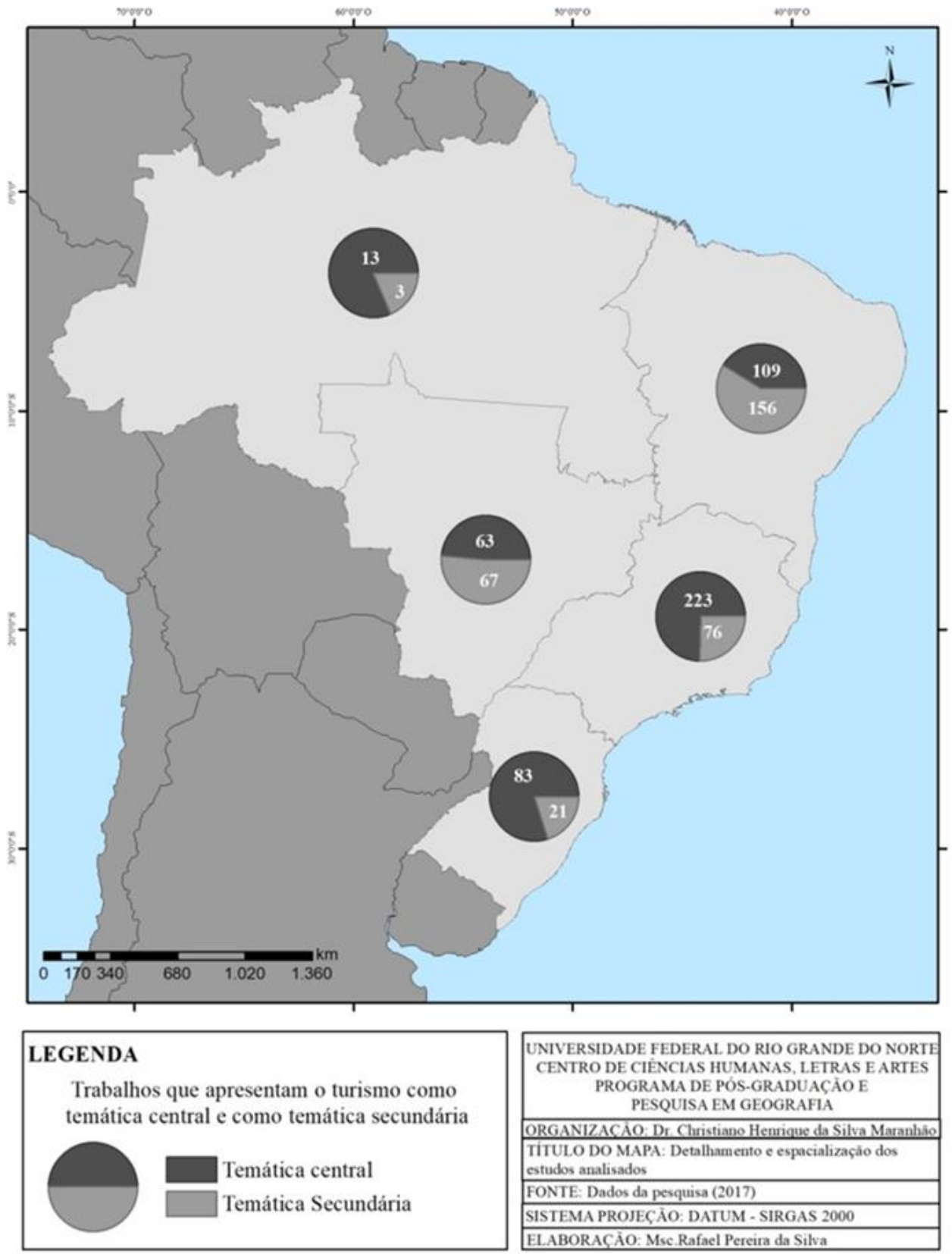

Fonte: dados da pesquisa, 2018

Identifica-se que a maior parte dos programas onde os estudos estão vinculados apresenta áreas de concentração que prescrevem uma análise espacial, diante de suas múltiplas dinâmicas, trabalhando com questões que versam sobre a estruturação, organização, produção, gestão, planejamento, monitoramento, sanções e impedimentos relacionados ao arranjo espacial. Atrelado a esta abordagem, nota-se o estudo do turismo fazendo relação com o conceito de território, de região, de lugar e de espaço geográfico, partindo dos 
desdobramentos que ocorrem a partir da gênese do contato da atividade turística com o elemento da paisagem natural (recurso).

Já no que tange aos desdobramentos positivos do turismo no espaço, os estudos destacam as análises sobre dinamização da economia das localidades, geração de emprego e renda (direta e indireta), a valorização de culturas locais (culinária, religiosidade), retratam a relação presente no par dialético global versus local. Em estudos pontuais verifica-se um embate da atividade do turismo. De um lado, identifica-se a necessidade de promover a atividade fazendo uso dos recursos naturais, e de outro lado, observa-se a necessidade de ações de preservação desses mesmos recursos, vistos como importantes para a operacionalização da atividade do turismo no Brasil.

Ainda vale pontuar a relevância da temática de turismo para o cenário da pósgraduação em Geografia no Brasil, informando que na Universidade Federal de Minas Gerais (UFMG) existe uma especialização intitulada de Turismo e Desenvolvimento Sustentável, e que na Universidade Estadual de Londrina (UEL) já se estuda com bastante ênfase a segmentação do Turismo Rural.

No que se refere aos estudos geográficos (teses e dissertações) que analisam o turismo de forma secundária, é permitido sinalizar um quantitativo de 323 pesquisas que tratam da temática do turismo como complemento e/ou composição da conjuntura analisada. Para esses casos, o emprego da temática do turismo não forneceu parâmetros suficientes para classificálo como cerne da pesquisa.

Ainda é possível verificar, no Mapa 1, que os estudos geográficos (teses e dissertações) que abordam o turismo de forma central se sobressaem em quatro regiões do país, com exceção para a região nordeste. Ao aprofundar na leitura, identificou-se uma expressiva conjuntura marcada pela migração de pesquisadores entre as regiões nordeste e sudeste, facilitada pelas parcerias institucionais e por bolsas de estudo, as quais possibilitaram que pesquisadores nordestinos estudassem seus cenários particulares em outras instituições. Fato identificado no sentido inverso também.

Meditando ainda sobre os estudos que tratam do turismo de forma secundária, as temáticas e os objetos de análise identificados são diversos, e tratam do turismo como um partícipe (positivo ou negativo) da dinâmica macro dos recortes estudados. A diferença em relação aos estudos que tratam do turismo de forma secundária é que o turismo é apenas mais um componente, dentro dos inúmeros agentes dos contextos abordados, não sendo ele causa imediata das realidades identificadas. Observa-se o turismo como coadjuvante, revelando-se 
como mais uma atividade econômica que compõe e dinamiza a área e/ou o objeto de estudo das pesquisas, não aparentando centralidade que influenciasse as análises e conclusões.

Por exemplo, cita-se o estudo que trata da necessidade de avanços e ampliação de logística dos meios de transporte e deslocamento das regiões e/ou localidades. Neste caso, o turismo se insere no momento em que se pauta os transportes e deslocamentos motivados ou em torno da atividade turística. Ainda pode-se mencionar algumas pesquisas que abordam a teoria dos circuitos da economia urbana de Milton Santos (renomado geógrafo brasileiro), em uma determinada área, e acaba identificando o turismo como um dos seus eixos estruturantes.

Antes de expor as conclusões, reflete-se brevemente sobre as IES e os programas de pós-graduação stricto sensu em Geografia que não apresentam estudos com a temática do turismo. Para estes casos é permitido destacar que, dentre um quantitativo de 65 programas brasileiros de pós-graduação em Geografia, apenas 21 não apresentaram afinidade com a pesquisa do turismo. Para isso, pontuam-se algumas explicações sobre a inexistência de estudos que tratam do turismo nos aludidos programas. A princípio, é evidente que alguns programas ainda não apresentam estudos que tratam do turismo devido a sua recente data de fundação, e que no período da análise não contabilizava tempo hábil para defesa de uma tese e/ou dissertação.

Ponderando sobre as áreas de concentração, nota-se que algumas delas centralizam suas pesquisas em função de uma alguma localidade específica, como é o caso da UFAM/AM, que direciona suas produções para temáticas referentes à Amazônia. Em outros casos, identifica-se a centralidade das pesquisas sobre os elementos naturais e/ou biomas de características particulares, como é o caso do programa ligado à UFG sediado no Campus Jataí, que elege o elemento "Cerrado". Em outros programas nota-se que a perspectiva física da Geografia é fomentada com notoriedade. Essa postura acaba inibindo possíveis usos do turismo como temática de pesquisa, uma vez que a perspectiva humana é representativa nas análises do turismo. Menciona-se o caso da UFT/TO, que norteia suas pesquisas para o tratamento da dinâmica geoterritorial e geoambiental.

\section{CONSIDERAÇÕES FINAIS}

Diante da conjuntura analisada, conclui-se que a temática do turismo para estudos (teses e dissertações) vinculados aos programas brasileiros de pós-graduação stricto sensu em Geografia é de significativa relevância e apresenta centralidade no momento de estruturar os 
estudos, seja para defender ou denunciar o turismo. Destarte, a ciência geográfica continua se qualificando como uma das ciências que mais se dedica aos estudos acadêmicos do turismo.

É possível inferir que a relação estabelecida pauta-se numa perspectiva de cooperação, onde se pode notar ganhos para o turismo e para a Geografia. Para o turismo (e turismólogos), a principal benesse é a demanda pela utilização de paradigmas científicos consolidados para validar suas pesquisas, uma vez que o turismo ainda vivencia um processo evolutivo e construtivo de suas bases epistemológicas.

Já para a ciência geográfica (e geógrafos), essa relação com o turismo possibilita um complexo campo de teste para aplicação e validação de conceitos, teorias e métodos geográficos específicos. É notório o uso da temática do turismo possibilitando a operacionalização teórico-metodológica dos conceitos-chave da geografia (espaço geográfico, paisagem, lugar, região e território), dentre outros exemplos.

Observa-se que as interferências (econômicas, políticas, socioculturais, ambientais dentre outras) que o turismo promove no arranjo espacial, com o suporte dos avanços técnicos, são os principais subsídios que aproximam a pesquisa geográfica da temática do turismo.

Diante desse cenário complexo, identifica-se a relação entre Geografia e o turismo baseada na sinergia entre o fomento de materialidades (infraestruturas urbanas ou turísticas, criadas e/ou reordenadas) e na forma como elas são utilizadas pelos sujeitos (sejam eles locais e/ou visitantes que se deslocam pelo espaço). Destacando fixos (objetos) e fluxos (relações), eixos estruturantes do saber geográfico, em dinâmica constante com a práxis do turismo.

Portanto, para além de uma simples área que sofre preconceitos infundados na academia, o turismo se revela como uma significativa temática para a Geografia, chegando a impulsionar, em algumas situações, linhas de pesquisa no âmbito da pós-graduação. A expectativa é que, com o avanço das técnicas paralelo ao fomento do turismo, os estudos e análises geográficas aumentem em números e em complexidade, por meio de diferentes problematizações que surgem a partir da forma como o turismo é gerenciado e planejado.

\section{REFERÊNCIAS}

ACERENZA, M. A. Administração do turismo, Edusc, Bauru, 2002.

AZEVEDO, F.F; FIGUEIREDO, S.J.L; NÓBREGA W.R.M \& C.H.S MARANHÃO. Turismo em foco, NAEA, Belém, 2013. 
BARRETTO, M \& SANTOS, R. J. DOS. Fazer científico em turismo no Brasil e seu reflexo nas publicações, Turismo-visão e ação, 7(2): 357-364, 2005.

BECKER, E.L.S. Geografia e turismo: uma introdução ao estudo de suas relações, Rosa dos ventos, Universidade de Caxias do Sul, 6(1):52-65, 2014.

BARDIN, L. Análise de conteúdo, Edições 70, Lisboa, 2004.

CAPES, COORDENAÇÃO DE APERFEIÇOAMENTO DE PESSOAL DE NÍVEL SUPERIOR. Banco de teses: sobre o banco de teses. Disponível em: http://bancodeteses.capes.gov.br/noticia/view/id/3. (consultado em 02/06/2015)

CARLOS, A. F. A geografia brasileira, hoje: algumas reflexões", Terra Livre, São Paulo, 1(18): 161-178, 2002.

CASTRO, N. A. R. DE. O lugar do turismo na ciência geográfica: contribuições teóricometodológicas à ação educativa", tese (doutorado em geografia), Universidade de São Paulo, São Paulo, 2006.

CRUZ, R. DE. C. Política de turismo e território, Contexto, São Paulo, 2000.

DANTAS, A. Introdução à ciência geográfica. In: Dantas, A \& Hortêncio, T. (Org.), Edufrn, Natal, p. 210-225, 2011.

DENCKER, A. F. M Estado de Educação no Brasil: O caso do ensino em turismo". In: Congresso Brasileiro de Ciências da Comunicação, Intercom, Brasília, 2006.

ENDRES, A. V. As políticas de turismo e os novos arranjos institucionais na Paraíba/Brasil, tese (doutorado em sociologia política), Universidade Federal de Santa Catarina, Florianópolis, 2012.

GASTAL, S. Turismo: investigação e crítica”, Contexto, São Paulo, 2002.

GIL, A.C. Métodos e técnicas de pesquisa social, Atlas, São Paulo, 2007.

GONÇALVES, H. DE A. Manual de monografia, dissertação e tese, (2), Avercamp, São Paulo, 2005.

HOLANDA, L. A. DE; WIDMER, G.M \& LEAL, S.R. A produção científica em turismo no Brasil: reflexões e proposições a partir de um estudo revisional, IX Seminário da Associação Nacional Pesquisa e Pós-Graduação em Turismo, Universidade Anhembi Morumbi, São Paulo, 2012.

ISKANDAR, J. I. Normas da ABNT: comentadas para trabalhos científicos", (5), Juruá, Curitiba, 2012.

JAFARI, J. La cientifización del turismo, Estudios y Perspectivas en Turismo, 3(1): 7-36, 1994.

JAFARI. J. El turismo como disciplina científica: sociología del turismo, política y sociedade", (1) 42: 36-56, 2005. 
KÖCHE, J. C. Fundamentos de metodologia científica: teoria da ciência e iniciação à pesquisa, (32), Ed. Petrópolis, Vozes, Rio de janeiro, 2013.

LIMA, J. R. DE \& REJOWSKI, M. Ensino superior em turismo no Brasil: a produção acadêmica de dissertações e teses (2000-2009)", Revista Brasileira de Pesquisa em Turismo. 5(3): 406-432, 2011.

MARANHÃO, T. DE P. A. Produção interdisciplinar de conhecimento científico no Brasil: temas ambientais", Revista Sociedade e Estado, (3) 25, 2010.

MENEGHEL, S. M. Produção de conhecimento no contexto brasileiro: perspectivas de instituições emergentes", Atos de Pesquisa em Educação, 3 (2): 444-460, 2007.

MORAES, A. C. R. Geografia: pequena história crítica, Hucitec, São Paulo, 2007.

MOREIRA, R. Pensar e ser em geografia: ensaios de história, epistemologia e ontologia do espaço geográfico, Contexto, São Paulo, 2007.

MOREIRA, R. O pensamento geográfico brasileiro: as matrizes clássicas originárias". 2. Contexto, São Paulo, 2014.

NECHAR, M. C. Epistemología critica del turismo ¿qué es eso?", Turismo em análise, 3 (22), Universidade de São Paulo, São Paulo, 2011.

PANOSSO NETTO, A \& TRIGO, L. G.G. Educação e pesquisa em turismo no Brasil, Revista Turismo \& Desenvolvimento. 26: 9-16, Universidade de Aveiro. Portugal, 2016.

PLATAFORMA SUCUPIRA. Cursos avaliados e reconhecidos, Disponível em: https://sucupira.capes.gov.br/sucupira/public/consultas/coleta/programa/quantitativos/quantita tivoIes.jsf?areaAvaliacao=36\&areaConhecimento=70600007. Consultado em 1/07/2018.

PRITCHARD, A., \& MORGAN, N. De-centring Tourism's Intellectual Universe, or Traversing the Dialogue Between Change and Tradition", In: I. Ateljevic, A. Prichard, \& N. Morgan (Org), The critical turn in tourism studies: innovative research methods, pp: 1128, Elsevier, Amsterdam, 2007.

REJOWSKI, M. Caracterização da produção científica sobre Turismo no Brasil: Estudo documental das teses de doutorado (1990 a 2005)", Anais do Seminário da Associação Nacional Pesquisa e Pós- Graduação em Turismo, (7), São Paulo, 2010.

REJOWSKI, M. Turismo e pesquisa científica: pensamento internacional $\mathrm{x}$ situação brasileira", Papirus, Campinas, São Paulo, 1996.

RICHARDSON, R. J. Pesquisa social: métodos e técnicas, (7), Atlas, São Paulo, 2008.

RODRIGUES, A. B. Turismo e espaço: rumo a um conhecimento transdisciplinar, (3), Hucitec, São Paulo, 2001.

SANTOS, M \& SOUZA, M. A. A. DE. A construção do espaço, Nobel, São Paulo, 1996.

SANTOS, M. Por uma geografia nova: da crítica da geografia a uma geografia crítica" (6), Editora da Universidade de São Paulo, (Coleção Milton Santos), São Paulo, 2004. 
SILVA, A. C. DA SILVA. O litoral norte do estado de São Paulo: formação de uma região periférica", tese (doutorado em geografia), Universidade de São Paulo, São Paulo, 1975.

SILVA, C. H. C. DA. O turismo e a produção do espaço: perfil geográfico de uma prática socioespacial”, Geografia Ensino \& Pesquisa, 2(16), 2012.

SCHLÜTER, R. Investigación en turismo y hoteleira. CIET, Buenos Aires, 2000.

URRY, J. The Tourist gaze: leisure and travel in contemporary societies, Theory, culture and society, Sage, London, 1990.

VEAL, A. Metodologia de pesquisa em lazer e turismo, Tradução de Gleice Guerra e Mariana Adligue. Aleph (Série turismo), São Paulo, 2011.

Recebido em Outubro de 2017

Aprovado em Dezembro de 2018

Publicado em Fevereiro de 2018 